\title{
PROYECTOS DE INVESTIGACIÓN Y LOS DERECHOS DE PROPIEDAD INDUSTRIAL EN LA UNIVERSIDAD PÚBLICA - CASO UNMSM
}

\author{
Carlos Armas Morales* \\ E-mail: karmas_88@hotmail.com \\ Wilfredo Armas Morales*** \\ E-mail:kwarmas_88@hotmail.com
}

\begin{abstract}
RESUMEN
El presente trabajo tiene como objetivo identificar a un grupo de investigación de la Universidad Nacional Mayor de San Marcos a fin de reorientar en los derechos de propiedad industrial, que son generadores de economía y al mismo tiempo permiten la acreditación de calidad y pertinencia social de la universidad.
\end{abstract}

Palabras clave: Derechos de propiedad industrial, investigaciones.

\section{ABSTRACT}

This current work has the aim of guiding San Marcos University Researchers in all issues regarding industrial copyright which are economy generators and at the same time allowers university quality accreditation and social pertinence.

Keywords: Industrial copyrights, researchers.

\section{INTRODUCCIÓN}

Si partimos que la universidad cumple con tres fines fundamentales que son docencia, investigación y proyección social ${ }^{1}$, rescatamos que el factor común es el conocimiento, fundamentado en los dos primeros fines como medios para obtener un producto que se configure en la satisfacción de las necesidades sociales, propiciando la proyección social de la universidad. Es decir, el conocimiento es el factor esencial para el desarrollo de un país siempre y cuando éste se concentre o se aplique a la realidad de un país, región o ciudad, apuntando de esta manera a la pertinencia y la razón de ser de la universidad.

De otro lado, son dos los productos genéricos que proporciona la universidad a la sociedad. Hablamos de bienes y servicios entendidos desde una óptica diferente a la que tienen las empresas que buscan rentabilidad económica individual o grupal sobre lo social, ya que la universidad es una institución que satisface en forma primordial a la sociedad a través de sus proyecciones y acciones generadoras de bienes

* Magíster en Derecho. Abogado e Ingeniero. Docente de la Facultad de Ciencias Administrativas (UNMSM). 
y servicios con rentabilidad social, siendo la rentabilidad económica un medio para lograr sus fines.

Así, por ejemplo, si logramos a base de las investigaciones obtener una vacuna que luego podemos producir, inferimos que la búsqueda de la universidad es satisfacer las necesidades primordiales de salud de la comunidad en el sentido de combatir la enfermedad, logrando una rentabilidad social con la buena salud de la comunidad; y de otro lado, las invenciones e innovaciones de un producto o bien puede ser una posibilidad de rentabilidad económica al generar contratos rentables de Licencia, Royalties, etc., además de retroalimentarlos hacia nuevas investigaciones, dado que "la producción del conocimiento, función esencial de la Universidad, se halla muy relegada particularmente en el área estratégica de ... la producción de tecnologías"2.

Por tanto la investigación, dentro del conglomerado del conocimiento, constituye un escalón esencial del ejercicio docente que procura resolver la problemática que acontece a la sociedad, lo que justifica reconsiderar el conjunto de investigaciones de la Universidad para analizarlas y fundamentar su orientación hacia los fines loables del desarrollo y bienestar social.

Expresado así, en relación a esto último, encontramos un acoplamiento interesante entre las investigaciones que genera la universidad y los derechos de propiedad Industrial ${ }^{3}$; lo que nos ha motivado a revisar estudios similares en los últimos años con resultados negativos, por lo que se hizo perentorio gestar esta nuestra iniciativa, teniendo en cuenta que la UNMSM señala como una acción importante el "Proteger la propiedad intelectual y promover el registro de patentes"4; y donde se inserta el empresariado privado teniendo en cuenta que la universidad debe "Promover y gestionar relaciones e interacciones entre la Universidad y su entorno, particularmente con el sector empresarial en el área de investigación e innovación tecnológica", los cuales convergen en la producción de patentes e innovaciones por parte de la universidad y en el uso de estos bienes por parte de las empresas, claro está, previas relaciones contractuales, para lo cual es necesario buscar los mecanismos técnicos-jurídicos adecuados para la comercialización y explotación de estos derechos intangibles limitado a las investigaciones de la UNMSM y seleccionados como proyectos innovadores por el Vicerrectorado de Investigación, así como los proyectos especiales que cuentan con financiamiento propio.

Por lo que este trabajo, en una fase preliminar, tiene como objetivo evaluar las investigaciones realizadas en nuestra Universidad ${ }^{6}$ para incentivar este tipo de investigación, al amparo de "...los derechos de propiedad intelectual... patentes, diseño industrial... que otorgan poder al mercado sobre la competencia a los inventores y creadores y recompensan, así a la innovación e inversión en $I+D^{\text {"7 }}$; y de otro, ligar a la Universidad en forma sinérgica con el empresariado.

\section{MÉTODO}

El presente estudio explora las investigaciones que se orientan a los derechos de propiedad industrial. Para ello se consideran 314 trabajos de investigación innovadores realizados en la UNMSM hasta el 2006, material recopilado del Vicerrectorado de Investigación, además se han considerado diez proyectos ganadores con financiamiento especial para el periodo 20022006. Las investigaciones analizadas se han seleccionado en base a los siguientes criterios:

- Se incluyen como proyectos de investigación a las creaciones e innovaciones de diseños, procesos, modelos o secretos industriales.

- Se excluyen los proyectos de investigación que están protegidos por otras formas tales como softwares, bases de datos, etc., que pertenecen a los derechos de autor u otras formas de protección.

- Se excluyen los proyectos de investigación que inciden en la salud de la sociedad, obviamente sin potencialidad a derechos de propiedad, así como los estudios de diagnóstico, formulaciones teóricas y evaluaciones descriptivas que no están protegidas por los derechos intelectuales.

\section{RESULTADOS Y DISCUSIÓN}

La evaluación de los proyectos desarrollados hasta el 2006 y difundidos por la Universidad Nacional Mayor de San Marcos según los criterios indicados en el Método, nos permite verificar las potencialidades y posibilidades de los mismos, en función de identificar proyectos que deriven en propiedad industrial, obteniendo los resultados descritos en los cuadros siguientes (ver Cuadro № 1 y Cuadro № 2). 
Cuadro № 1. Proyectos especiales aprobados con financiamiento y su evaluacion como elemento de derechos de propiedad intelectual (DPI) ${ }^{8}$.

\begin{tabular}{|c|c|}
\hline INVESTIGACIÓN & CALIFICA PARA DPI \\
\hline $\begin{array}{l}\text { PEM2006A14. Extracción y fraccionamiento } \\
\text { supercrítico del aceite esencial de mintyhostachys } \\
\text { setosa (muña) para aplicaciones farmacéuticas }\end{array}$ & $\begin{array}{l}\text { Califica para patentes, dado que se } \\
\text { formula un fármaco. }\end{array}$ \\
\hline $\begin{array}{l}\text { PEM2006A23. Desarrollo de una sistema de detección } \\
\text { temprana de la sequía en el Perú a partir de imágenes } \\
\text { de satélite e índices de la oscilación sureña del Niño. }\end{array}$ & $\begin{array}{l}\text { Investigación que genera rentabilidad } \\
\text { social. }\end{array}$ \\
\hline $\begin{array}{l}\text { PEM2006B02. Seroprevalencia de anticuerpos contra } \\
\text { HTVL-1 en mujeres en edad reproductiva consultantes } \\
\text { del Instituto de Medicina Tropical - UNMSM. }\end{array}$ & $\begin{array}{l}\text { Investigación médico social, genera } \\
\text { rentabilidad social. }\end{array}$ \\
\hline $\begin{array}{l}\text { PEM2006B04. Desarrollo del Método Sol-Gel para la } \\
\text { preparación de nuevos materiales en la UNMSM. }\end{array}$ & $\begin{array}{l}\text { La técnica SOL Gel es susceptible a } \\
\text { procesos y formulaciones patentables } \\
\text { u otros derechos. }\end{array}$ \\
\hline $\begin{array}{l}\text { PEM2006B06. Genómica funcional de alpaca: } \\
\text { asociación de Est (Expressed Sequence Tags) y finura } \\
\text { de fibra en alpacas (Vicugna pacos) ... }\end{array}$ & $\begin{array}{l}\text { Cuando hay técnica existe una } \\
\text { predisposición para registro de } \\
\text { derechos industriales. }\end{array}$ \\
\hline $\begin{array}{l}\text { PEM2006B08. Diferenciación de micobacterium SPP } \\
\text { mediante PCR y análisis del polimorfismo de longitud } \\
\text { de los fragmentos de restricción (PCR-RFLP) del gen } \\
\text { hsp65. }\end{array}$ & $\begin{array}{l}\text { Investigación médico social, genera } \\
\text { rentabilidad social. }\end{array}$ \\
\hline $\begin{array}{l}\text { PEM2006B19. Síntesis y caracterización de } \\
\text { hidroxiapatita obtenida a partir de recursos orgánicos } \\
\text { desechables. }\end{array}$ & $\begin{array}{l}\text { Se estudia procesos, en consecuencia } \\
\text { es susceptible de derechos de } \\
\text { propiedad industrial }\end{array}$ \\
\hline $\begin{array}{l}\text { PEM2006B28. Polimorfismo i/d del gen ACE en } \\
\text { pacientes afectados por la nofropatía diabética de las } \\
\text { tres regiones del país. }\end{array}$ & $\begin{array}{l}\text { Investigación médico social, genera } \\
\text { rentabilidad social. }\end{array}$ \\
\hline $\begin{array}{l}\text { PEM2006B30. Nueva técnica de reconocimiento del } \\
\text { bacilo tuberculoso. }\end{array}$ & $\begin{array}{l}\text { Investigación médico social, genera } \\
\text { rentabilidad social. }\end{array}$ \\
\hline $\begin{array}{l}\text { PEM2006C25. Nación, racismo y género en la prensa } \\
\text { sensacionalista. }\end{array}$ & Está sujeto a derecho de autor. \\
\hline
\end{tabular}

Fuente: Vicerrectorado de Investigación (2006). Boletín No 1. UNMSM, Octubre 2006.

Elaboración: Del autor a partir de la relación de proyectos ganadores.

Cuadro № 2. Resumen de proyectos especiales9 .

\begin{tabular}{|c|c|c|}
\hline TOTAL DE PROYECTOS & SÍ CALIFICA DPI & NO CALIFICA DPI \\
\hline 10 & 4 & 6 \\
$\%$ & $40 \%$ & $60 \%$ \\
\hline
\end{tabular}

Fuente: Vicerrectorado de Investigación (2006). Boletín No 1. UNMSM, octubre de 2006. Elaboración: Del autor.

En relación a estos proyectos especiales, vale recordar que de los diez proyectos, cuatro califican o son asequibles a derechos de propiedad industrial y cinco tienen el mérito explícito de satisfacer las necesidades sociales relativas a la salud, complementando la proyección social de la Universidad, sin desmerecer al único proyecto de investigación de humanidades que convalida la formación integral que brinda la universidad, puesto que a decir de diversos tratadistas "En San Marcos la variada experiencia de la investigación humanística debes constituirse en la base para la formación de nuestros estudiantes" ${ }^{9}$. Los citados proyectos, a criterio del autor, armonizan con las potencialidades de la universidad. 
En el Cuadro № 3 observamos que de todos los proyectos innovadores solo el $43 \%$ tiene perspectivas para ser considerado como proyecto coadyuvante a ser propiedad industrial, lo que conlleva a insistir en que los trabajos de investigación conducentes a propiedad industrial deben tener cierta cobertura en la universidad, por lo que se les debe conceder una mejor difusión sin que la universidad descuide otras prioridades.

Cuadro № 3. Proyectos innovadores y su evaluacion como elemento de Derechos de Propiedad Intelectual (DPI) ${ }^{10}$.

\begin{tabular}{|l|c|c|c|}
\hline \multicolumn{1}{|c|}{$\begin{array}{c}\text { TIPO DE } \\
\text { PROYECTOS }\end{array}$} & TOTAL & CALIFICA DPI & NO CALIFICA DPI \\
\hline General & 199 & 87 & 112 \\
Metalurgia & 37 & 26 & 11 \\
Telecomunicaciones & 14 & 2 & 12 \\
Energía & 7 & 2 & 5 \\
Agroindustria & 9 & 3 & 6 \\
Pesquería & 48 & 16 & 32 \\
Total & 314 & 136 & 178 \\
$\%$ & 100 & 43 & 57 \\
\hline
\end{tabular}

Fuente: Vicerrectorado de Investigación (2007). Proyectos innovadores presentados en la Cámara de Comercio de Lima por el Ingeniero Javier Del Carpio Gallegos.

Elaboración: Del autor a partir de relación de proyectos innovadores.

Se observa igualmente que el mayor número de proyectos atendibles en cuanto a derechos de propiedad industrial son los de metalurgia, debido a que hay mayor predisposición para ello por los investigadores de esas áreas; en el caso de electrónica, por su peculiaridad de involucrar el uso del software, su protección y aprovechamiento, no es materia de los derechos de propiedad industrial.

En cuanto al sector pesquero si bien presenta un gran número de investigaciones, la mayoría están orientadas a diagnosis, descripciones, estadísticas, etc., que son meritorias pero que no califican para relaciones de propiedad industrial; similar apreciación ocurre en proyectos innovadores de energía.

En cuanto a las limitaciones de las observaciones, referimos que el análisis se hizo en base a resúmenes y/o títulos de las citadas investigaciones, aclarando que algunas de las no calificadas como potenciales derechos de propiedad podrían derivar en relaciones patrimoniales de propiedad industrial no percibidas en el presente estudio, en base a la inquietud y capacidad del propio investigador del proyecto en el transcurso de su realización.
Concluyendo y en relación a la muestra observada, creemos que se deben seleccionar o hacer concursos con mayor especificidad en relación a las investigaciones que conducen a propiedad industrial, y específicamente a patentes para inventos e innovaciones (modelos de utilidad), de tal manera que se tenga mayor presencia de este tipo de investigaciones. Por supuesto que con ello no estamos expresando que no demos interés a otras investigaciones de humanidades o de tipo social que también fluyen por la Universidad en el cumplimiento de sus fines. De lo que se trata es de cubrir investigaciones que de alguna manera generen ingresos económicos a la UNMSM, y por lo mismo, sean contribuyentes para todo tipo de investigación, sin dejar de lado la importancia de enlazar a la universidad con la empresa en función del desarrollo sostenible del país. Desde esa óptica, debe buscarse una relación armónica en todo el conjunto de las investigaciones producidas por la Universidad, lo cual involucra sostener un equilibrio entre la investigación y los objetivos aparentemente comerciales de esta casa de estudios, de tal manera que no se desvirtúe su esencia o finalidad académica, profesional y humanística. 
Sabedores del valor de la Propiedad Industrial es necesario que se tome en cuenta el derecho de los patentes y el licenciamiento del uso de los mismos a las empresas, conforme ha sido viable en otras latitudes como en Estados Unidos a través de la Ley Bogh-Dole, aprobada en 1980 que permitió que las universidades patenten y negocien con mayor frecuencia estos derechos en el mercado, siendo un catalizador de beneficios sociales y económicos de la financiación pública de la investigación ${ }^{11}$.

En nuestro caso, el Estado debe garantizar a la universidades que los derechos de Propiedad Industrial generados con fondos públicos pueden ser explotados a través de ingresos por licencias sobre patentes y royalties, contratos de know how, provisión de conocimientos y secretos industriales, hasta la obtención de un mayor número de contratos de investigación con empresas en conjunto o por encargo, lo que dará lugar a sinergias entre empresas y la universidad, además de fundamentar la acreditación universitaria de calidad y la pertinencia social de la institución universitaria.

Al respecto, la Ley Universitaria (Ley № 23733), tal como lo referimos en un trabajo anterior $^{12}$, no refiere norma alguna sobre la propiedad intelectual, dejando en libertad su regulación por los Estatutos de las universidades. El estatuto de la UNMSM regula en el Artículo № 214 que:

"Se reconoce el derecho de autor de los investigadores o inventores. Corresponde a la universidad otorgar las facilidades para registrar o patentar los resultados de los trabajos de investigación";

norma general que reconoce estos derechos pero sin mayores detalles.

Desde otra perspectiva, los estudios de los derecho de propiedad industrial en general nos llevan a informarnos sobre los contratos de licencia y de provisión de conocimientos técnicos, aunque no son pocas veces que vienen juntos, dándose una aparente conexión entre estas dos formas contractuales. No obstante es necesario esclarecer que la diferencia sustancial surge del hecho de que los contratos de Licencia vienen premunidos con un derecho público o patente que otorga el Estado a los inventores que les da mayor seguridad y ventajas de orden legal y público; mientras que los contratos de provisión de conocimientos en poder del poseedor, o sean no patentables, se hacen viables a través de la capacidad contractual para proteger sus derechos en el orden privado.

Los contratos de provisión de conocimientos son aquellos por los que se transfieren ciertos conocimientos técnicos no patentables, alternándose o no los derechos que sobre la utilización de tales conocimientos tiene el trasmisor o poseedor de conocimientos, pudiendo ser las transferencias a titulo temporal o definitivo. La doctrina la denomina contrato de know how, lo cual de acuerdo a nuestra legislación procederá sobre cualquier tipo de conocimiento o información no patentada. La doctrina califica a estos contratos en "conocimientos patentables pero no patentados; procedimientos técnicos que no son patentados; conocimientos llamados de orden empírico; y habilidad técnica"13.

Desde otra vertiente, las patentes son derechos que pueden ser transferidos por relaciones contractuales como los contratos de licencia, cuyas cláusulas en lo posible deben de ser favorables para la universidad, recomendando la experiencia internacional de cautelar estas creaciones, instando contractualmente a la otra parte a realizar esfuerzos de buena fe para la explotación de la invención. Igualmente, hasta donde sea posible, debe incluirse de alguna forma la limitación de la exclusividad geográfica o de área, para permitir que la tecnología pueda ser utilizada por más de una empresa. Los contratos sobre patentes pueden ser por contratos de licencia y de cesión de derechos, en este último caso "...el titular de ella transfiere en propiedad todos los derechos emergentes de su calidad de propietario industrial, a su contratante" 14 .

Se deja en claro que la Universidad puede participar con las empresas en join ventures o Consorcios de Investigación, siendo necesario que la Universidad se provea de cuadros de gestión de tecnologías para optimizar estas negociaciones, tal como lo recomienda la OCDE.

"El éxito que pueden tener las OPIS a la hora de comercializar su PI dependerá en gran medida de sus recursos humanos y en particular en la disponibilidad de los profesionales de transferencia tecnológica con una formación a la vez científica y empresarial..."15.

Lo que conlleva a organizar la formación de cuadros especializados y adecuar las inver- 
siones de ciencia en tecnología, ponderando los gastos de inversión entre el profesional científico y de gestión.

\section{CONCLUSIONES}

1. La UNMSM no tiene estudios selectivos que evalúen en forma concreta la proyección de las investigaciones que deriven en inventos o innovaciones que procuren licencias o royalties y provisión de conocimientos de know how.

2. Para lograr una mayor cantidad de este tipo de investigaciones es necesario que sean delineadas a través de políticas especiales, dadas sus características y naturaleza tecnológica particular.

3. La gestión de productos intangibles o patentes u otros deben ser materia de preparación especializada de los funcionarios de dirección y gestión de transferencias de tecnología.

4. Los ingresos obtenidos de los derechos de propiedad industrial deben ser usados para propiciar nueva investigaciones o a fines conducentes a los mismos o similares objetivos.

5. La dirección y gestión debe este tipo de investigaciones debe estar al más alto nivel a fin de que se les dé la importancia debida.

"Los rectores de de las universidades y directores de las OPIs debes integrar la gestión del PI en sus planes de gestión de la investigación. Una forma de llevar esto a cabo consiste en hacer que los responsables de las operaciones de transferencia despachen directamente con los rectores de las universidades $y / 0$ directamente de investigación". ${ }^{16}$

\section{NOTAS}

1. El Artículo № 116 del Estatuto de UNMSM, en relación al docente, indica: "Los profesores de la Universidad de San Marcos ejercen funciones de enseñanza aprendizaje, investigación y proyección social...".

2. Ministerio de Educación (2006). La Universidad en el Perú. Informe 2006. p. 84.

3. El Decreto legislativo № 823 , Ley de Propiedad Industrial, es la que rige actualmente en al ámbito nacional desde el 4 de mayo de 1996. Esta ley se adecúa a la Constitución de 1993, y protege a once elementos constitutivos de la propiedad industrial, a saber: a) Patentes de invención.

b) Certificados de protección.

c) Modelos de utilidad.

d) Diseños industriales.

e) Secretos industriales.

f) Marca de productos o servicios.

g) Marcas colectivas.

h) Marcas de certificación.

i) Nombre comerciales.

j) Lemas comerciales.

k) Denominaciones de origen.

4. Vicerrectorado de Investigación. Boletín s/n. UNMSM.

5. Op. Cit.

6. Para los fines de nuestro estudio y concordante con las investigaciones de los investigadores de la UNMSM, indicamos y describimos los siguientes elementos:

a) Patentes e inventos: Se entiende por patente el título por el cual el Estado concede el derecho exclusivo de explotación al titular de una invención dentro del territorio nacional.

b) Certificado de propiedad: Se extiende a los proyectos de invención que necesiten experimentar o construir un mecanismo que obligue a hacer pública su idea.

c) Modelos de utilidad (innovaciones): Es una patente que se otorga a toda nueva forma de configuración o disposición de elementos de algún artefacto, herramienta, instrumento, mecanismo u otros instrumentos de un objeto o parte del mismo, que permiten un mejor o diferente funcionamiento, utilización, fabricación del objeto que lo incorpora o que le proporciona alguna utilidad, ventaja o efecto técnico que antes no tenia.

d) Diseños industriales: Son registrables y se otorgan a cualquier reunión de líneas, combinación de colores o cualquier forma externa bidimensional o tridimensional.

e) Secretos industriales: Es el conocimiento tecnológico integrado por procedimientos de fabricación o producción en general, como el conocimiento relativo al empleo y aplicación de técnicas industriales, resultante de conocimiento, experiencia habilidad intelectual que guarda una persona con carácter confidencial y que le permita obtener o mantener una ventaja competitiva y económica frente a terceros.

De estos elementos, los inventos son patentables y en forma temporal se expiden certificaciones de propiedad de posibles de inventos. Asimismo existen patentes de modelos de utilidad: se registran los diseños de utilidad y certifican notarialmente los secretos industriales, estos últimos no tienen las prerrogativas que garantizan a las patentes, sin embargo pueden ser objetos de transferencias o cesiones a través de contratos privados.

7. Organización para la Cooperación y el Desarrollo Económico (OCDE) (2003). Resúmenes de Investigación de Mercado: Gestión de Propiedad Intelectual para los organismos públicos de investigación. Ver en página web: www.oecd.org./bookshop/.

8. Vicerrectorado de Investigación (2006). Boletín $N^{0} 1$. UNMSM, Octubre 2006.

9. Op. Cit.

10. Vicerrectorado de Investigación (2007). Proyectos innovadores presentados en la Cámara de Comercio de Lima por el Ingeniero Javier Del Carpio Gallegos. 
11. OCDE. Op. Cit.

12. En el Perú existen dos leyes que regulan la propiedad intelectual: la Ley de Derechos de Autor (Decreto Legislativo № 822) y La Ley de Propiedad Industrial (Decreto Legislativo № 823). Con este alcance corregimos igualmente el error material de trascripción numérica en el articulo anterior "Inventos y Patentes en la UNMSM. Reflexiones en un marco de acreditación universitaria sobre el docente investigador, creador e innovador", publicada en: Revista Gestión en el Tercer Milenio (2006). Volumen № 9, Edición № 18, pp. 83-90.

13. Cabanellas (1980), p.80.

14. Sandoval (1992), p.92.

15. OCDE. Op. Cit. Se citan algunas siglas que procedemos a aclarar: Oficinas de Propiedad Industrial (OPIs); Oficinas de Transferencia de Tecnologías (OTTs); Propiedad Industrial (PI); Derechos de Propiedad Industrial (DPI).

16. OCDE. Op. Cit.

\section{BIBLIOGRAFÍA}

Armas, Carlos (2006). Inventos y Patentes en la UNMSM. Reflexiones en un marco de acreditación universitaria sobre el docente investigador, creador e innovador. En: Revista Gestión en el Tercer Milenio. Volumen № 9, Edición № 18, pp 83-90.
Cabanellas, Guillermo (1980). Contratos de licencia y de transferencia tecnológica. Buenos Aires, Editorial Heliasta SRL.

Congreso de la República. Ley de Propiedad Industrial del Perú. Decreto Legislativo № 823.

Sandoval, Ricardo (1992). Tratado de Derecho Comercial. Nueva operaciones mercantiles. Santiago de Chile, Editorial Jurídica Cono Sur Ltda.

Universidad Nacional Mayor de San Marcos (2006). Boletín Vicerrectorado de Investigación $s / n$. Universidad Nacional Mayor de San Marcos, artículo de Luz Hermoza, pp. 2-3.

Universidad Nacional Mayor de San Marcos (2006). Boletín Vicerrectorado de investigación $N^{o} 1$, octubre. Universidad Nacional Mayor de San Marcos. Artículo de Javier Verástegui, pp. 11-14.

Universidad Nacional Mayor de San Marcos. Estatuto de la Universidad Nacional Mayor de San Marcos, setiembre de 1984. 